
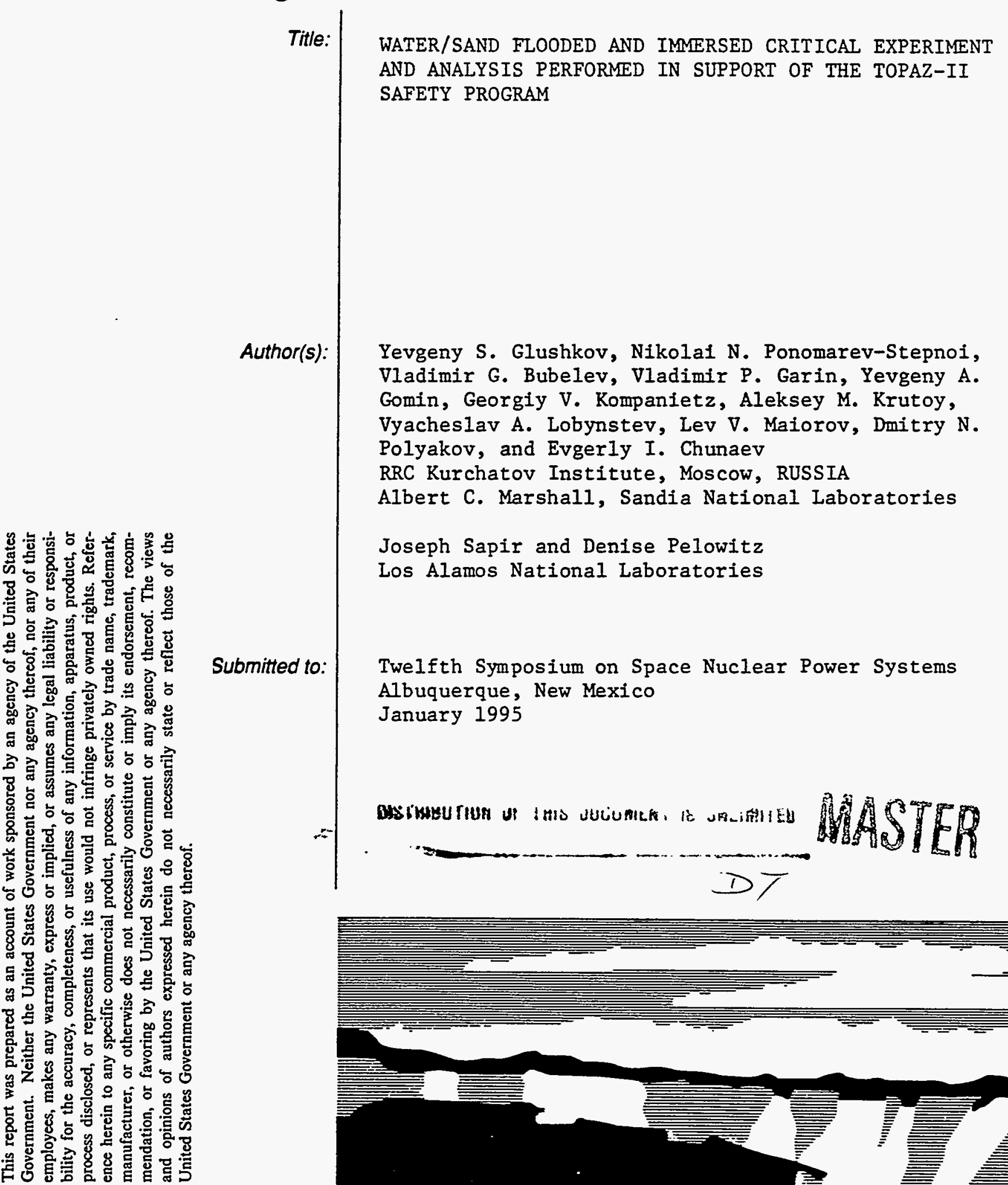

Author(s): Yevgeny S. Glushkov, Nikolai N. Ponomarev-Stepnoi, Vladimir G. Bubelev, Vladimir P. Garin, Yevgeny A. Gomin, Georgiy V. Kompanietz, Aleksey M. Krutoy, Vyacheslav A. Lobynstev, Lev V. Maiorov, Dmitry N. Polyakov, and Evgerly I. Chunaev RRC Kurchatov Institute, Moscow, RUSSIA Albert C. Marshall, Sandia National Laboratories

Joseph Sapir and Denise Pelowitz Los Alamos National Laboratories

Submitted to: Twelfth Symposium on Space Nuclear Power Systems Albuquerque, New Mexico January 1995
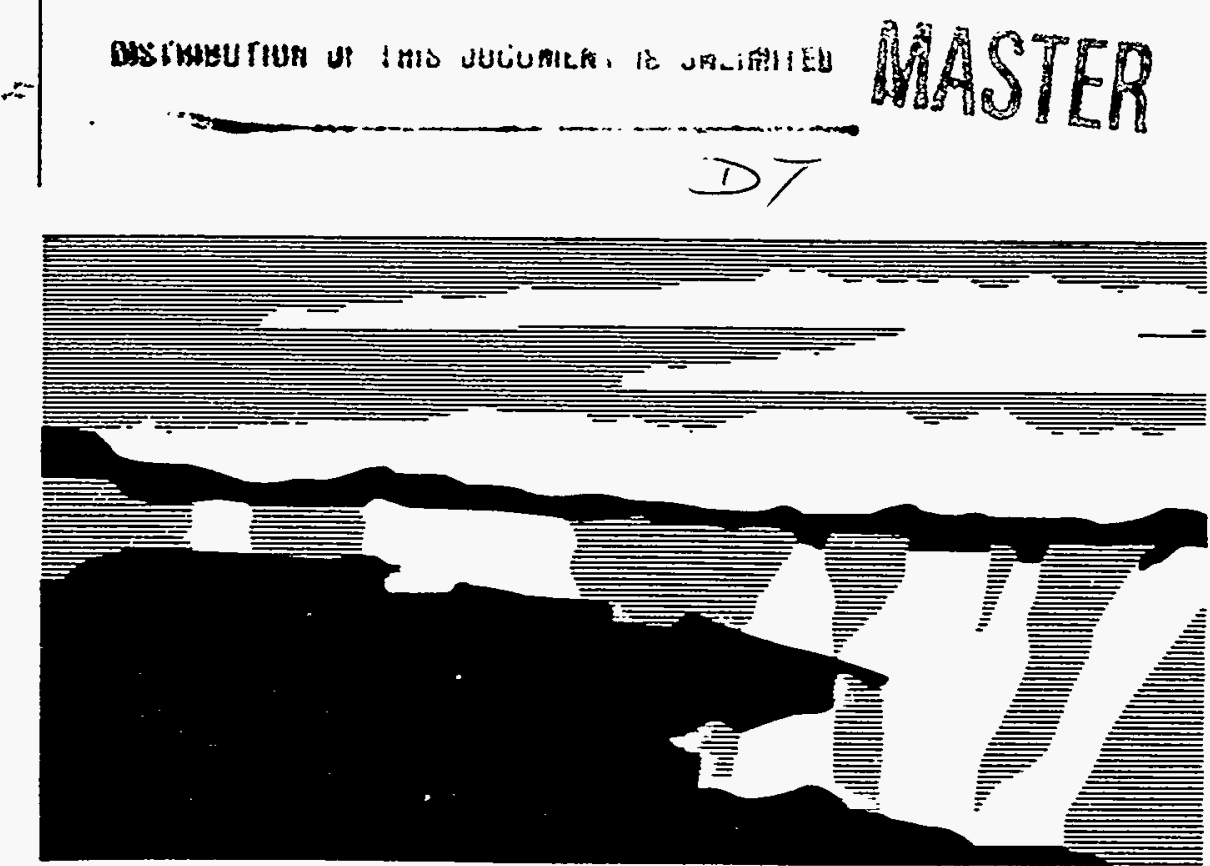

NATIONAL LABORATORY

Los Alamos National Laboratory, an affirmative action/equal opportunity emplofyer, is operated by the University of Calitomia for the U.S. Depanment of Energy under contract W.7405-ENG.36. By acceptance of this article, the publisher recognizes that the U.S. Government retains a nonexclusive, royalty-tree license to publish of reproduce the published form of this contribution, or to allow others to do so. for U.S. Government purposes. The Los Namos National Laboratory requests that the publisher identity this article as work performed under the auspices of the U.S. Department of Energy. 


\section{DISCLAIMER}

Portions of this document may be illegible in electronic image products. Images are produced from the best available original document. 


\title{
WATER/SAND FLOODED AND IMMERSED CRITICAL EXPERIMENT AND ANALYSIS PERFORMED IN SUPPORT OF THE TOPAZ-II SAFETY PROGRAM
}

\author{
Evgeny S. Glushkov, Nikolai N. Ponomarev-Stepnoi \\ Vladimir G. Bubelev, Vladimir P. Garin, \\ Evgeny A. Gomin, Georgy V. Kompanietz, \\ Aleksei M. Krutov, Vyacheslav A. Lobynstev, \\ Lev V. Maiorov, Dmitry N. Polyakov, \\ and Evgeny I. Chunyaev \\ RRC Kurchatov Institute \\ Moscow 123182, Russia

\begin{abstract}
Albert C. Marshall International Nuclear Safety Albuquerque, NM 87185
\end{abstract} \\ Sandia National Laboratories \\ USA \\ (505) 272-7002 \\ Joseph L. Sapir and Denise B. Pelowitz \\ Reactor Design and Analysis Group \\ Los Alamos National Laboratory \\ Los Alamos, NM 87545 \\ USA \\ (505) 667-7939
}

\section{CAMERA READY MANUSCRIPT prepared for:}

Twelfth Symposium

on Space Nuclear Power and Propulsion

Albuquerque, NM

8-12 January 1995

Date of submission: November 1, 1994

Author to whom correspondence should be sent:
Dr. Evgeny S. Glushkov RRC KI 123182 Moscow, Kurchatov Square 1, Russia 


\title{
WATER/SAND FLOODED AND IMMERSED CRITICAL EXPERIMENT AND ANALYSIS PERFORMED IN SUPPORT OF THE TOPAZ-II SAFETY PROGRAM
}

\author{
Evgeny S. Glushkov, Nikolai N. Ponomarev-Stepnoi \\ Vladimir G. Bubelev, Vladimir P. Garin, \\ Evgeny A. Gomin, Georgy V. Kompanietz, \\ Aleksei M. Krutov, Vyacheslav A. Lobynstev, \\ Lev V. Maiorov, Dmitry N. Polyakov, \\ and Evgeny I. Chunyaev \\ RRC Kurchatov Institute \\ Moscow 123182, Russia
}

\author{
Albert C. Marshall \\ International Nuclear Safety \\ Sandia National Laboratories \\ Albuquerque, NM 87185 \\ USA
}

(505) 272-7002

\author{
Joseph L. Sapir and Denise B. Pelowitz \\ Reactor Design and Analysis Group \\ Los Alamos National Laboratory \\ Los Alamos, NM 87545 \\ USA \\ (505) 667-7939
}

\begin{abstract}
Presented is a brief description of the Narciss-M2 critical assemblies, which simulate accidental water/wet-sand immersion of the TOPAZ-II reactor as well as water-flooding of core cavities. Experimental results obtained from these critical assemblies, including experiments with several fuel elements removed from the core, are shown. These configurations with several extracted fuel elements simulate a proposed fuel-out anticriticality-device modification to the TOPAZ-II reactor. Preliminary computational analysis of these experiments using the Monte Carlo neutron-transport method is outlined. Nuclear criticality safety of the TOPAZ-II reactor with an incorporated anticriticality unit is demonstrated.
\end{abstract}

\section{INTRODUCTION}

The TOPAZ-II space nuclear power system is a small, heterogeneous, intermediate-spectrum reactor that uses highly-enriched uranium-dioxide fuel and a zirconium-hydride moderator (Ponomarev-Stepnoi 1989). A crucial issue for space nuclear reactors is ensuring criticality safety at all stages of ground preparation, launch, and operation in the working orbit. It was shown by analytical investigation that one of the most severe emergency situations related to criticality safety is reactor immersion into water or wet sand with water penetration into the inner cavities of the reactor that can result in increased reactivity. As shown in preliminary studies, reactivity values obtained from computations in Russia and the United States (U.S.) are significantly different. Therefore, it was crucial to evaluate the methods for assessing nuclear criticality safety. Accordingly, special experiments were performed in 1993 to 1994 at the Narciss-M2 critical assembly. These experiments were conducted to study the effects of surrounding the assemblies with water and of allowing water penetration into the inner cavities of the critical assemblies that simulate the TOPAZ-II reactor, as well as to evaluate methods of assuring reactor subcriticality under these conditions. The results of these experiments and their tentative computational study by the Monte Carlo method are presented in this report.

\section{EXPERIMENTAL INVESTIGATIONS AND RESULTS}

Experimental studies of different critical-assembly configurations, under conditions of water and/or sand immersion and water filling of the reactor cavities, were pursued at the Narciss-M2 
facility. To study the possibility of a reactivity increase from water immersion and/or burial in sand, experiments were performed with the partial removal of fuel from the core and with absorbers and displacers inserted into central cavities of fuel elements. The experimental results for the main configurations of critical assemblies studied at the Narciss-M2 facility are described below:

- Configuration 0. This critical assembly with a beryllium radial reflector is unaffected by a water environment (i.e., without surrounding the assembly with water/sand or flooding the inner core cavities). The number of fuel elements is 37 , each of which has a height of $\mathrm{H}_{\mathrm{f}}=375 \mathrm{~mm}$. This critical assembly is assumed to be the initial point for the reactivity-effects evaluation for other configurations.

- Configuration 1. The radial beryllium reflector is dismounted and is replaced by a water radial reflector and experimental rotary drums filled with water. Inner cavities of the core are filled with water. The number of fuel elements is 37 , each having a height of $\mathrm{H}_{\mathrm{f}}=375 \mathrm{~mm}$.

- Configuration 2. The same as Configuration 1 , but four fuel elements are removed and the resulting void is filled with water. There are thus 33 fueled elements in this configuration.

- Configuration 3. The radial beryllium reflector is dismounted and is replaced by a wet-sand radial reflector and experimental rotary drums filled with water. Inner cavities of the core are filled with water. The number of fuel elements is 37, each having a height of $\mathrm{H}_{\mathrm{f}}=375 \mathrm{~mm}$.

- Configuration 4. The critical assembly with a beryllium radial reflector is surrounded with water. Inner cavities of the core are water-filled. The number of fuel elements is 34 , each having a height of $\mathrm{H}_{\mathrm{f}}=375 \mathrm{~mm}$.

The experiments were performed to obtain criticality for all configurations except Configuration 2, which was subcritical. Its subcriticality was measured by the source-jerk technique. Critical positions of drums and assembly reactivities for all configurations are given in Table 1. Other parameters of the critical assemblies that vary for different configurations, such as differences in fuel-pellet (FP) diameter, are also shown in this table.

\section{COMPUTATIONAL INVESTIGATION OF CRITICAL ASSEMBLIES}

The Monte Carlo method was used for computational study of the critical experiments because of the complex structure of the TOPAZ-II reactor and critical assemblies under investigation, as well as the physical properties of intermediate-spectrum, heterogeneous systems with highly enriched fuel. Computations were performed using the MCU (Russian) and MCNP (U.S.) codes. The calculational model was rather detailed to properly account for all gaps and cavities filled with water/sand in the experiments. Construction elements of the thermionic fuel element (TFE), fuel, control drums, and reflectors were considered by the calculational model. The results of calculational investigations and comparisons with experiments are shown in Table 2.

When the results of the experiments at the critical assemblies are compared with computational data it becomes apparent that computational codes based on the Monte Carlo method, as well as the neutron data used, provide agreement with the experiment. Thus, earlier computational data on nuclear criticality safety (with regard to the anticriticality unit) for the TOPAZ-II reactor (Sapir et al. 1994) are confirmed experimentally. These experiments also support the conclusion that the water-flooded TOPAZ-II reactor surrounded with wet sand has more reactivity than if it was water flooded and surrounded with water, although this difference is modest. As for dry sand surrounding the TOPAZ-II reactor, experiments showed that the reactor remains subcritical. 
TABLE 1. Critical Assemblies Configurations.

\begin{tabular}{|c|c|c|c|c|c|c|c|c|c|}
\hline \multirow[t]{2}{*}{$\#$} & \multirow[t]{2}{*}{ Description } & \multicolumn{7}{|c|}{ Critical Position of Drums $\left({ }^{\circ}\right)^{*}$} & \multirow{2}{*}{$\begin{array}{l}\text { Reactivity with } \\
12 \text { Drums } \\
\text { Withdrawn, } B_{\text {eff }}\end{array}$} \\
\hline & & SDs & CD\# 1 & CD\# 2 & $\mathrm{CD} \# 3$ & CD\# 4 & CD\# 5 & CD\# 6 & \\
\hline 0 & $\begin{array}{l}\text { Without water; } \\
\text { Beryllium reflector; } \\
37 \text { FP } \emptyset 17.0 \times 4.5 ; \\
\mathrm{H}_{\mathrm{f}}=375 \mathrm{~mm}\end{array}$ & 180 & 180 & 0 & 180 & 0 & 107 & 0 & +2.35 \\
\hline 1 & $\begin{array}{l}\text { Water filled cavities; } \\
\text { Water radial reflector; } \\
\text { 30 FP Ø17.0x4.5; } \\
7 \text { FP Ø17.9x8.0; } \\
\text { Hf=375 mm }\end{array}$ & 180 & 180 & 0 & 180 & 0 & 97 & 180 & +0.80 \\
\hline 2 & $\begin{array}{l}\text { Water filled cavities; } \\
\text { Water radial reflector; } \\
30 \text { FP } \emptyset 17.0 \times 4.5 ; \\
3 \text { FP } \emptyset 17.9 \times 8.0 ; \\
\mathrm{H}_{\mathrm{f}=375 \mathrm{~mm} ;} \\
\text { Fuel removed from } \\
\text { channels } 2,4,5,6 \text { and } \\
\text { replaced with water }\end{array}$ & - & - & - & - & - & - & - & -9.1 \\
\hline 3 & $\begin{array}{l}\text { Water filled cavities; } \\
\text { Wet sand radial reflector; } \\
37 \text { FP } \emptyset 17.0 \times 4.5 \text {; } \\
\mathrm{H}_{\mathrm{f}}=375 \mathrm{~mm}\end{array}$ & 180 & 0 & 180 & 0 & 180 & 36 & 0 & +1.19 \\
\hline 4 & $\begin{array}{l}\text { Water filled cavities; } \\
\text { Beryllium radial reflector } \\
\text { surrounded with water; } \\
34 \text { FP } \emptyset 17.0 x 4.5 ; \\
\text { Hf }=375 \mathrm{~mm} \text {; } \\
\text { Fuel removed from } \\
\text { channels } 2,4,6 \text { and replaced } \\
\text { with water. }\end{array}$ & 180 & 180 & 180 & 180 & 180 & 73 & 180 & +0.35 \\
\hline
\end{tabular}

* SDs represents the position of all six safety drums. CD\# $\mathbf{n}$ indicates the position of six individual control drums.

TABLE 2. Results of Critical Assemblies Calculations.

\begin{tabular}{|c|c|c|c|c|}
\hline \multirow[t]{2}{*}{$\#$} & \multicolumn{2}{|c|}{$k_{\text {eff }}$ for Criticality } & \multicolumn{2}{|c|}{$\begin{array}{l}\text { Reactivity with } 12 \text { Drums Withdrawn (\$) } \\
\qquad\left(B_{\text {eff }}=0.008\right)\end{array}$} \\
\hline & Experiment & Computation using MCU & Experiment & Computation using MCU \\
\hline 0 & 1.000 & $1.002 \pm 0.001$ & +2.35 & $\cdots$ \\
\hline 1 & 1.000 & $0.992 \pm 0.003$ & +0.80 & -- \\
\hline 2 & $\cdots$ & $0.924 \pm 0.003^{*}$ & -9.1 & -9.5 \\
\hline 3 & 1.000 & $0.991 \pm 0.002$ & +1.19 & -- \\
\hline 4 & 1.000 & $1.001 \pm 0.002$ & +0.35 & $\cdots$ \\
\hline
\end{tabular}

* With 12 drums withdrawn $\left(\varphi=180^{\circ}\right)$ 


\section{CONCLUSIONS}

The experimental and calculational study of the water-flooded and wet-sand-immersed reactor performed at the Narciss-M2 facility (RRC Kurchatov Institute, Russia) has supported the conclusion that neutron data and codes based on the Monte Carlo method used in the U.S. and Russia provide good agreement with the experiment. Thus, the earlier computational data for nuclear criticality safety of the TOPAZ-II reactor were confirmed by the experiment.

However, because there is some difference between computational data produced in the U.S. (MCNP code) and in Russia (MCU code) it will be necessary in the future to investigate in detail the reasons for this difference. This will allow further improvement of the anticriticality unit design for the TOPAZ-II reactor. Experimental data on the reactivity effect of the water-flooded and water/sand-immersed reactor obtained at the Narciss-M2 facility are sufficient for this purpose.

\section{Acknowledgment}

The experiments were performed at the RRC Kurchatov Institute (Russia) in 1993-1994 under contract with JSC INERTEK. Computational investigations were performed in cooperation with RRC Kurchatov Institute (Russia) and Los Alamos National Laboratory (U.S.).

\section{References}

Ponomarev-Stepnoi, N. N. (1989) "Nuclear Power in Space," Atomic Power, 66: 371.

Sapir, J. et al. (1994) "Pre-Orbital Criticality Safety for the NEPSTP Mission," in Proc. 11th Symposium on Space Nuclear Power and Propulsion, DOE CONF-940101, M. S. El-Genk and M. D. Hoover, eds., American Institute of Physics, New York, AIP Conference Proc. No. 301, 3: 1043-1051. 